\title{
An Experimental Study on Incidental Vocabulary Acquisition: Incidental Vocabulary Acquisition in Foreign Language by Visual Literary Quotations
}

\author{
Nazmiye Gürel Cennetkuşu, Hüseyin Koç, Esra Teker Kozcaz \\ School of Foreign Languages, Harran University, Şanlıurfa, Turkey \\ Email: ngurel@harran.edu.tr, huseyinkoc@harran.edu.tr, esratkozcaz@harran.edu.tr
}

How to cite this paper: Gürel Cennetkuşu, N., Koç, H. and Teker Kozcaz, E. (2020) An Experimental Study on Incidental Vocabulary Acquisition: Incidental Vocabulary Acquisition in Foreign Language by Visual Literary Quotations. Open Access Library Journal, 7: e6176.

https://doi.org/10.4236/oalib.1106176

Received: February 28, 2020

Accepted: March 16, 2020

Published: March 19, 2020

Copyright $\odot 2020$ by author(s) and Open Access Library Inc.

This work is licensed under the Creative Commons Attribution International License (CC BY 4.0).

http://creativecommons.org/licenses/by/4.0/

(c) (i) Open Access

\begin{abstract}
Depending on the power and influence of the incidental learning, some of the thematic words such as days, months, seasons, numbers, school rules are hung in coloured strips on some school or class walls in our country and recently on the school stair steps. Students are expected to see these words every day and learn the words while trying to understand the contents. Such practices are usually seen at primary or high school level, because students at higher education institutions are considered not interested in these contents due to their age. In this study, it was investigated whether a similar extra curriculum-based method had any contributions in the acquisition of vocabulary in a foreign language by taking into consideration the age and level variables at Harran University School of Foreign Languages.
\end{abstract}

\section{Subject Areas}

Second and Foreign Language Teaching, English Language Teaching

\section{Keywords}

Incidental, Vocabulary, Vocabulary Acquisition, Poster, Digital Visual, Literature Quote, Higher Education, Foreign Language Teaching

\section{Introduction}

The international language of communication is English because it is the international language of science. The importance and impact of the rapid dissemination of English in the fields of academic circles and academic communication 
cannot be ignored [1] [2]. For these reasons, teaching English is very important in academic areas. An increasing number of universities in many countries of the world offer undergraduate and graduate programs in English, where English is the second or foreign language.

An important aspect of the English programs at the higher education in these countries offer English preparatory programs that students take as an obligatory part of the programs they enroll in or on an optional basis. Following one-year intensive language training, students are expected to communicate in a second or foreign language at a certain level-both written and oral. The basis for establishing a healthy communication in any language is the vocabulary acquisition and improving language proficiency.

As discussed in [3], it stated that students at higher education level should acquire/learn incidentally instead of memorizing the majority of words in the target foreign language by doing direct word studies. Hence, incidental word acquisition refers to vocabulary acquisition/learning without a direct aim of acquiring/learning new words. In other words, while students focus on the meaning of the written or oral message given to them in academic assignments, learning/acquiring new words is defined as incidental vocabulary acquisition.

There are many different and successful strategies to increase and enrich incidental vocabulary acquisition, especially through classroom reading activities. However, every potential opportunity seems to be used to help ESL (English as a Second Language) and EFL (English as a Foreign Language) students become more successful in the target language. For this reason, it is a common tradition for English teachers to decorate their classes with the students' own works, to help students to be exposed to content in the target language and to get the target items accidentally. Today, such practices are frequently seen in the common areas of schools. Teachers not only embellish the walls of their school with visual elements prepared by students, but also use stair steps to provide students with more target languages. The visual elements affixed to the staircases usually include days, months, seasons, numbers and/or greetings, and the word elements of this target language are presented in a coloured way to the students. It is not known whether such decorations applied by teachers have attracted the attention of students, or whether it helps students to acquire/learn the elements of the target language, since there are no studies conducted in this area.

\section{Research Questions}

In this case study, 1) it has been tried to determine whether incidental vocabulary acquisition can be increased through visual aids outside the classroom and 2) visual aids with elements of target language are effective at higher education level.

\section{Literature Review}

Vocabulary acquisition, which is one of the basic components of language 
learning, plays a key role in learning and developing a foreign language. The acquisition of new words for the target language is directly proportional to the frequency of encountering these words in the inputs to which the students are exposed [4] [5] and how they can manipulate these words in their minds [6] [7]. But; there is no fixed quantity related to the frequency of encounter required for vocabulary acquisition, and there are no activities that are sure to maximize word processing [3] [8] [9]. However, it is assumed that reading studies are a powerful resource for vocabulary acquisition in the target language; moreover, these studies alone provide word acquisition [10] [11] [12] [13] [14].

Regardless of the language skills of the foreign language courses (speaking, listening, writing or reading), the students' vocabulary have a significant share. In addition, extracurricular activities and methods are sometimes used to facilitate students' vocabulary acquisition and offer options to them. However, despite everything; many of the foreign language students are constantly experiencing the hardship of a heavy burden such as word acquisition, and do not know how to deal with a very arduous job such as storing thousands of new words in their memory to use when needed. This has been scientifically proven by numerous surveys, interviews and case studies [15] [16] [17] [18].

In the study [19], there is no clarity about how many words foreign language students should know in the target language. However, there are enough experimental data that the perceptual vocabularies of native English-speaking students are between 14,000 words and 17,000 words [20]. In the literature on foreign language learning, the acquisition of 5000 basic words by students is generally considered to be the minimum acquisition goal to fulfill the tasks and tasks to be applied [21] [22] [23]. However, there are strong arguments that this minimum value may not be sufficient. As in [24], it is stated that readers should be familiar with $95 \%$ of the words in the text in order to be fully understood. As discussed in [19], it is stated that readers are required to have at least 10,000 basic words in the text of a general text.

Many scientists agree that most of the words of the target language are coincidentally learned when searching for the meaning of the words they do not know in order to make the general meaning of the part they read or when they are reading comprehensively [9] [24] [25]. In such cases, word learning is called incidental because the word learned here is not the main purpose of the study but its by-product [6] [10] [24] [26] [27] [28] [29]. According to the word acquisition literature in the mother tongue and foreign language, a) most of the words are learned "incidentally", in other words, they are learned as a by-product when applying student listening, reading, speaking and writing activities and b) a limited number of words are also learned "deliberately", namely, they are learned as a target [21] [30] [31] [32] [33].

Coincidental or indirect word learning, that is, word acquisition although the main focus is not to worry about vocabulary, is shown as one of the most effective ways to learn the meanings of words from the contents encountered [10] [28] [30] [34]. As discussed in [35], it has been proved that when the foreign 
language students read for meaning, vocabulary acquisition occurs incidentally, and students do not have a lack of learning to learn while learning vocabulary.

Many researchers [31] [36] [37] state that students' procedures for processing input affect incidental learning. All these researchers emphasize the importance of "getting attention" and believe that incidental learning is hidden in some small details that focus on trying to understand the general theme. Depending on the power and effects of incidental learning, the words of the week days, months, seasons, numbers and school rules are adhered in colour strips to some school or classroom walls in our country and recently to the school stair treads and the students are expected to see these words every day and learn the words while trying to understand the content. Such practices are generally seen at primary or high school level, because it is thought that students who study in higher education institutions will not be interested in these contents due to their age.

In this study, which was carried out in Harran University School of Foreign Languages, it was investigated whether a similar extra-curricular method contributed to the acquisition of foreign language vocabulary by considering age and level variables.

In the first phase of the project, a pre-test was applied based on measuring only the vocabulary to determine the vocabulary of the students. Afterwards, posters prepared with selective quotations from British and American literature were hung on the corridors and columns of the School of Foreign Languages, which has English preparatory school and these posters were kept hanging on the walls for at least one and a half months in order to create interest and familiarity with the students. At the end of the term, a post-test was applied, and the students were asked how much they learned from the words in the literary quotations in the hanging posters. In addition, a semi-structured group interview was held with volunteer students and student opinions were taken about the benefit of posters. The aim of the study is to determine how extracurricular activities and visual elements allow incidental word acquisition in students.

In the second phase of the project, posters on the walls and in the classrooms were removed; instead of the posters, LCD screens mounted on the corridor walls of the school. In these screens, the content in the posters was reflected regularly every day, the same processes and steps followed for the posters were repeated.

Research questions:

Does visual input provided to student except for lesson contribute to foreign language acquisition?

Do these visuals support especially vocabulary acquisition in a foreign language?

\section{Materials and Methods}

This study is an experimental study that uses both quantitative and qualitative data collection. The quantitative part of the study consists of the data obtained from the pre and post-tests. In the qualitative part, in-depth interviews were 
conducted with students who participated in the study. The data obtained through interviews completed the data collected from the tests performed in the quantitative step of the study, thus obtaining a more complete and detailed picture.

\subsection{Participants}

The sample of the study is composed of newly enrolled university students who are in the English Preparatory School at Harran University School of Foreign Languages.

\subsection{Data Collection and Data Analysis}

In accordance with the purposes of the study, posters containing literary quotations were prepared and pre-test and post-test were applied to the students. For the collection of qualitative data, semi-structured interviews were conducted with volunteer students. The pre-test, which was designed to determine the level of students' knowledge about the selected words, was applied at the beginning of the fall semester before the students started their lessons. All 102 students participated in the test. Although the questions were in a multiple-choice form, the tests were read and scored by two different evaluators. Peer evaluators reliability rate is determined as $100 \%$.

After the pre-test, the walls of the college in common areas are equipped with posters prepared for this study, containing the word elements in the target language. Some of the literary quotations in the post are as follows: "Even the smallest person can change the course of the future." (J. R. R. Tolkien, The Lord of the Rings), "Words are, in my not-so-humble opinion, our most inexhaustible source of magic." (J. K. Rowling, Harry Potter and the Deadly Hollows), "Suspicion always haunts the guilty mind." (William Shakespeare). A total of twenty-five posters were hanged on the walls of the two corridors where the classrooms were located, and the students were exposed to new words presented through the contents of these visual aids during an education/teaching period. Students were not instructed to regularly read literary quotes on posters and the words presented in the posters were not reported to be subject to tests.

At the end of the semester, students were given the final test. It has been tried to determine whether the chosen words that students are exposed to incidentally make difference in vocabulary acquisition/learning. The final tests were evaluated and scored by two different evaluators with $100 \%$ reliability. Ten students participated in the semi-structured interviews after the final tests were evaluated. The duration of voice recorded conversations ranged from 5 minutes to half an hour. All interviews were taken into the text and their contents were categorized after their transcriptions were made. Interview data were examined and crosschecked. A code is then given to each category and subcategory. After testing and evaluating the content presented through posters on the walls, the same content was presented to a different group of students on LCD screens, just like 
on posters, students were regularly exposed to the same content every day. All the processes and the steps taken for the posters were applied to the contents presented on the LCD screens and The quantitative data collected from the pre-test and post-test were combined with the qualitative data obtained from the interviews with the selected volunteer students.

\section{Research Findings and Discussion}

In this section, the descriptive analyses of the quantitative and qualitative data obtained as a result of the research study will be presented under the title of findings and the evaluations of the findings will be discussed in the sub-heading of discussion and suggestions.

\subsection{Findings}

Within this study, firstly poster work was applied. During the spring semester of the academic year 2016/2017, a pre-test was conducted to measure how many of the words selected from the words found in the literary quotations are known; the posters were then hung on the walls in the common areas of the school. At the end of the term, posters adorned the walls were removed and pre-prepared final test applied to the students, which measures the words measured by the pre-test with a different content.

The descriptive statistics of the pre-test where 77 students participate and the arithmetic average of the points that the students participated in the test are presented in Table 1.

As seen in Table 1, 77 students participated in the pre-test and twenty-seven of the students concentrated between 21 and 30 points. The arithmetic average of the 77 students who participated in the test was calculated as 25.75 .

Table 1. Descriptive statistics of pre-test for poster study.

\begin{tabular}{cc}
\hline Score Ranges & Number of Students \\
\hline $1-10$ & 24 \\
$11-20$ & 27 \\
$21-30$ & 6 \\
$31-40$ & 4 \\
$41-50$ & 3 \\
$51-60$ & 1 \\
$61-70$ & 1 \\
$71-80$ & 0 \\
$81-90$ & 0 \\
$91-100$ & 77 \\
TOTAL & 25.75 \\
OVERALL & \\
\hline
\end{tabular}


After the pre-test of the poster study and posters were kept on the walls until the end of the term, a final test was applied to all students. The descriptive statistics of the last test and the arithmetic average of the grades taken by the students are presented in Table 2 .

As shown in Table 2, the arithmetic average of the points taken by the students was calculated as 23.93 and it was seen that the student density was collected between $11-20$ and 21 - 30 points as in the pre-test.

The final stage of the poster study was the semi-structured interviews applied to a group of students selected by random sampling method. As of the day of the final test of the study, interviews were conducted with 10 randomly chosen students among the students registered in the school and the interviews were recorded in the voice recording and the text.

According to the data obtained from the interviews, the students found the posters interesting and wondered the contents:

"The posters you hung on the walls were definitely interesting. Backgrounds and colours of text on the posters... I'm very interested in all of them."

"The posters drew my attention from the first day because I came here to learn English. I knew it was something you hang on the wall for us."

The students stated that they used different methods to understand the content of the posters that attracted their attention. While some students wrote new words and sentences in their books, some other students tried to learn new words from the dictionary.

"I took pictures of some of the sentences written on posters, and I wrote some of them in my notebooks."

"I could more or less understand some of the sentences, but there were some sentences I didn't understand. I used translation tools and dictionaries to understand them."

Table 2. Descriptive statistics of the final test of the poster study.

\begin{tabular}{cc}
\hline Score Ranges & Number of Students \\
\hline $1-10$ & 28 \\
$11-20$ & 27 \\
$21-30$ & 13 \\
$31-40$ & 2 \\
$41-50$ & 2 \\
$51-60$ & 0 \\
$61-70$ & 0 \\
$71-80$ & 0 \\
$81-90$ & 1 \\
$91-100$ & 81 \\
TOTAL & 23.93 \\
OVERALL & \\
\hline
\end{tabular}


"I wondered what the quotes on the posters meant. As I saw the posters on the walls, I learned the words I did not know from the dictionary and tried to get the meanings of the sentences."

"I believe the posters help me learn some words, because after a while, I could understand written sentences without the need for a dictionary anymore."

Another noteworthy finding is that students indicate their anxiety as a motivation factor. The students used expressions to confirm the judgment of "not tested, not learnt".

"If you said you were going to test these words, it would be different; I mean I'd work harder. Obviously, it wasn't like working for the exam, in our free time, we wondered and tried to understand."

In the fall semester of the 2017/2018 academic year, the LCD screen study was started with a different group of English preparatory students. In the LCD screen work, the same content as the posters were digitally prepared, a pre-test was applied to all college enrolled students, and the literary quotations used in the posters were purchased in the project and reflected on the LCD screens mounted on the walls in the common areas of the school.

The descriptive statistics of the pre-test where 60 students participated, and the arithmetic average of the grades taken by the students are presented in Table 3.

According to Table 3, more than half of the 60 students participating in the pre-test were charged to only two of the ten points range, and 40 students in the $11-20$ and $21-30$ points range. As seen in the same table, the ratio of the total of the test score taken by each of the 60 students who participated in the pre-test to the number of students entering the test was calculated as 18.01. In other words, the arithmetic mean of the scores of 60 students who participated in the LCD screen study from the pre-test of this study was lower than the students' scores obtained from the tests of the same study participated in the poster study.

Table 3. Descriptive statistics of pre-test for LCD display.

\begin{tabular}{cc}
\hline Score Ranges & Number of Students \\
\hline $1-10$ & 14 \\
$11-20$ & 20 \\
$21-30$ & 20 \\
$31-40$ & 6 \\
$41-50$ & 0 \\
$51-60$ & 0 \\
$61-70$ & 0 \\
$71-80$ & 0 \\
$81-90$ & 0 \\
$91-100$ & 0 \\
TOTAL & 60 \\
OVERALL & 18.01 \\
\hline
\end{tabular}


LCD screens were kept open on the walls during the fall period, and the texts composed of literary quotations were shown to students at the college between 08.00 and 17.00 every day. The descriptive statistics and the arithmetic average of the grades taken by the students are presented in Table 4 .

As seen in Table 4, only 31 students participated in the final test of the LCD screen study. The reason for this is that students who have been absent at the end of the fall semester have dropped out attending school. The score range of the students participating in the test did not change in the last test, and 10 of the 31 students participating in the test were in the range of 21 - 30 points. The arithmetic average of the grades taken by the students was calculated as 20.61, and a difference of 2.60 points was found between the average of pre-test and post-test.

As in the case of poster work, the quantitative data obtained from the LCD screen study were also supported by qualitative data collected through semistructured student interviews after the final test. Semi-structured interviews were conducted between five minutes and half an hour with a group of 10 students formed by random sampling method. All interviews were recorded in the voice recording and the text.

When the semi-structured student interviews conducted on the LCD screen study were qualitatively analysed, it was seen that students were interested in the constantly changing visuals on the screen, similar to the students in the poster study:

"Frankly, the sentences on the screens caught my attention I'm here because I want to learn English and I want to understand and know everything in English."

Table 4. Descriptive statistics of the last test of LCD screen study.

\begin{tabular}{cc}
\hline Score Ranges & Number of Students \\
\hline $1-10$ & 6 \\
$11-20$ & 10 \\
$21-30$ & 7 \\
$31-40$ & 0 \\
$41-50$ & 0 \\
$51-60$ & 0 \\
$61-70$ & 0 \\
$71-80$ & 0 \\
$81-90$ & 0 \\
$91-100$ & 31 \\
TOTAL & 20.61 \\
OVERALL &
\end{tabular}


According to the results of the interview, the students followed similar paths and tried to learn the words they did not know and understand the sentences:

"Firstly, I looked up the words I did not know from dictionary in order to get the meaning of sentences. There were words I have already known."

In order to understand a sentence in a foreign language, it is not necessary to know the exact meaning of all words. A sentence or text written in a foreign language can also be understood correctly through inference. One of the objectives of skill-based reading is to give this skill to the student. According to the interview data, the students were able to comprehend the meaning of the sentences even though they could not "get the exact meanings of the words" they encountered:

"When I looked at the words to understand the sentences I got the meaning of the sentences, but I did not remember the words. I mean, maybe because I didn't repeat them, they are gone in my mind. But still there were words that I remembered. I mean I said to myself I have seen it before."

"Firstly, I translated all of the sentences using translation tools to understand. But then I got used to it and the sentences on the screens were constantly changing; I just started to understand looking up the words I didn't know."

"I can say that this screen and writings on the screen definitely taught me new words. I've become familiar with a lot of words that I don't know."

"Even if I didn't know all the words, when I look at the sentences on the screens, some of them look familiar. I'm trying to remember the words I never thought of while reading the sentences."

Similar to the statements of the students in the poster study, students participating in this study also believe that evaluating the learning of words (taking an exam) will change their learning behaviours and results:

"If you had told us that the words we saw on the screens would appear in a test, the situation would have been different. Words and phrases were probably draws more attention to me. Now I'm just curious because it draws my attention; but then it would be consciously. I mean I would look up consciously."

\subsection{Discussion and Suggestions}

According to the semi-structured student interviews carried out in the final sections of both phases of the study, the contents of both the posters in the school's common areas and the contents transferred via the LCD screens have been a new source of motivation for the students, helping them to learn/acquire new words.

Qualitative data also show that both types of content servers were found to be remarkable by the students, and the meanings of the sentences composed of literary quotations were highly curious by the students. Students have tried to acquire new words by using methods such as using a dictionary and taking notes. In addition, they experienced the technique of inference and began to acquire the skill by seeing its usefulness.

The most important of the qualitative findings is perhaps the exam motivation 
of the students. It has been observed that the fact that a word or structure will be asked in the examination and/or will be subject to any formal evaluation causes students to be more interested and to change their learning methods. The result of this is to increase students' intrinsic motivation and to make learning an autonomous process.

Despite the positive data provided by the qualitative data, the results of the analysis of the quantitative data did not result in a significant, statistically significant difference between the preliminary tests and the final tests. In fact, it did not help students to acquire new words from the content filled with literary quotations in the common areas of the college, equipped with posters or LCD screens.

The most important result in the study is to make students motivated by using all the possibilities - not only in order to ensure the effective learning of foreign language, but also in terms of incidental word acquisition-and to turn students into autonomous learners by transforming this motivation into intrinsic motivation.

The study can be repeated with longer and/or different presentations. It can be investigated whether exposure to new words for longer periods will change quantitative results. Different contents-such as parallel to the course contentcan be prepared and tested whether the students' achievements differ in terms of content. The effects of the evaluation drive can be investigated.

\section{Acknowledgements}

This study was funded by the Scientific Research Board of Harran University (Project No. 17083).

\section{Conflicts of Interest}

The authors declare no conflicts of interest regarding the publication of this paper.

\section{References}

[1] Ammon, U. (2007) Global Scientific Communication: Open Questions and Policy Suggestions. AILA Review, 20, 123-133. https://doi.org/10.1075/aila.20.11amm

[2] Hamel, R.E. (2007) The Dominance of English in the International Scientific Periodical Literature and the Future of Language Use in Science. AILA Review, 20, 53-71. https://doi.org/10.1075/aila.20.06ham

[3] Cho, K.S. and Krashen, S.D. (1994) Acquisition of Vocabulary from the Sweet Valley Kids Series: Adult ESL Acquisition. Journal of Reading, 37, 662-667.

[4] Nation, P. and Ming-Tzu, K.W. (1999) Graded Readers and Vocabulary. Reading in a Foreign Language, 12, 355-380.

[5] Webb, S. (2007) The Effects of Repetition on Vocabulary Knowledge. Applied Linguistics, 28, 46-65. https://doi.org/10.1093/applin/aml048

[6] Hulstijn, J.H. (2001) Intentional and Incidental Second-Language Vocabulary Learning: A Reappraisal of Elaboration, Rehearsal and Automaticity. In: Robinson, 
P., Ed., Cognition and Second Language Instruction, Cambridge University Press, Cambridge, 258-286. https://doi.org/10.1017/CBO9781139524780.011

[7] Laufer, B. and Hulstijn, J. (2001) Incidental Vocabulary Acquisition in a Second Language: The Construct of Task-Induced Involvement. Applied Linguistics, 22, 1-26. https://doi.org/10.1093/applin/22.1.1

[8] Krashen, S. (1989) We Acquire Vocabulary and Spelling by Reading: Additional Evidence for the Input Hypothesis. The Modern Language Journal, 73, 440-464. https://doi.org/10.1111/j.1540-4781.1989.tb05325.x

[9] Huckin, T. and Coady, J. (1999) Incidental Vocabulary Acquisition in a Second Language: A Review. Studies in Second Language Acquisition, 21, 181-193. https://doi.org/10.1017/S0272263199002028

[10] Day, R. and Omura, C.M. (1991) Incidental EFL Vocabulary Learning and Reading. Reading in a Foreign Language, 7, 541-551.

[11] Krashen, S.D. (2004) The Power of Reading: Insights from the Research: Insights from the Research. ABC-CLIO.

[12] Lehmann, M. (2007) Is Intentional or Incidental Vocabulary Learning More Effective. The International Journal of Foreign Language Teaching, 3, 23-28.

[13] Lee, S.Y. and Hsu, Y.Y. (2009) Determining the Crucial Characteristics of Extensive Reading Programs: The Impact of Extensive Reading on EFL Writing. The International Journal of Foreign Language Teaching, 5, 12-20.

[14] Ponniah, R.J. (2011) Incidental Acquisition of Vocabulary by Reading. The Reading Matrix, 11, 135-139.

[15] Gu, Y. and Johnson, R.K. (1996) Vocabulary Learning Strategies and Language Learning Outcomes. Language Learning, 46, 643-679. https://doi.org/10.1111/j.1467-1770.1996.tb01355.x

[16] Jones, F.R. (1995) Learning an Alien Lexicon: A Teach-Yourself Case Study. Second Language Research, 11, 95-111. https://doi.org/10.1177/026765839501100202

[17] Porte, G. (1988) Poor Language Learners and Their Strategies for Dealing with New Vocabulary. ELT Journal, 42, 167-172. https://doi.org/10.1093/elt/42.3.167

[18] Sanaoui, R. (1995) Adult Learners' Approaches to Learning Vocabulary in Second Languages. The Modern Language Journal, 79, 15-28. https://doi.org/10.1111/j.1540-4781.1995.tb05410.x

[19] Hazenberg, S. and Hulstun, J.H. (1996) Defining a Minimal Receptive SecondLanguage Vocabulary for Non-Native University Students: An Empirical Investigation. Applied Linguistics, 17, 145-163. https://doi.org/10.1093/applin/17.2.145

[20] Zechmeister, E.B., D’anna, C.A., Hall, J.W., Paus, C.H. and Smith, J.A. (1993) Metacognitive and Other Knowledge about the Mental Lexicon: Do We Know How Many Words We Know? Applied Linguistics, 14, 188-206. https://doi.org/10.1093/applin/14.2.188

[21] Nation, I.S.P. (1993) Vocabulary Size, Growth, and Use. In: Schreuder, R. and Weltens, B., Eds., The Bilingual Lexicon, John Benjamins, Amsterdam, 115-134. https://doi.org/10.1075/sibil.6.07nat

[22] Goulden, R., Nation, P. and Read, J. (1990) How Large Can a Receptive Vocabulary Be? Applied Linguistics, 11, 341-363. https://doi.org/10.1093/applin/11.4.341

[23] Laufer, B. (1992) How Much Lexis Is Necessary for Reading Comprehension? In: Vocabulary and Applied Linguistics, Palgrave Macmillan, London, 126-132. https://doi.org/10.1007/978-1-349-12396-4 12 
[24] Dupuy, B. and Krashen, S.D. (1993) Incidental Vocabulary Acquisition in French as a Foreign Language. Applied Language Learning, 4, 55-63.

[25] Paribakht, T.S. and Wesche, M. (1997) Vocabulary Enhancement Activities and Reading for Meaning in Second Language Vocabulary Acquisition. Second Language Vocabulary Acquisition: A Rationale for Pedagogy, 55, 174-200. https://doi.org/10.1017/CBO9781139524643.013

[26] Pigada, M. and Schmitt, N. (2006) Vocabulary Acquisition from Extensive Reading: A Case Study. Reading in a Foreign Language, 18, 1.

[27] Pitts, M., White, H. and Krashen, S. (1989) Language Acquirers. Reading in a Foreign Language, 5, 271.

[28] Saragi, T., Nation, P. and Meister, G. (1978) Vocabulary Learning and Reading. System, 6, 70-78. https://doi.org/10.1016/0346-251X(78)90027-1

[29] Waring, R. and Nation, I.S.P. (2004) Second Language Reading and Incidental Vocabulary Learning. Angles on the English Speaking World, 4, 97-110.

[30] Nagy, W.E., Herman, P.A. and Anderson, R.C. (1985) Learning Words from Context. Reading Research Quarterly, 20, 233-253. https://doi.org/10.2307/747758

[31] Schmidt, R. (1994) Deconstructing Consciousness in Search of Useful Definitions for Applied Linguistics. Consciousness in Second Language Learning, 11, 237-326.

[32] Shu, H., Anderson, R.C. and Zhang, H. (1995) Incidental Learning of Word Meanings While Reading: A Chinese and American Cross-Cultural Study. Reading Research Quarterly, 30, 76-95. https://doi.org/10.2307/747745

[33] Sternberg, R.J. (1987) Most Vocabulary Is Learned from Context. In: McKeown, M.G. and Curtis, M.E., Eds., The Nature of Vocabulary Acquisition, Erlbaum, Hillsdale, 89-105.

[34] Jenkins, J.R., Stein, M.L. and Wysocki, K. (1984) Learning Vocabulary through Reading. American Educational Research Journal, 21, 767-787. https://doi.org/10.3102/00028312021004767

[35] Kweon, S.O. and Kim, H.R. (2008) Beyond Raw Frequency: Incidental Vocabulary Acquisition in Extensive Reading. Reading in a Foreign Language, 20, 191.

[36] Craik, F.I. and Tulving, E. (1975) Depth of Processing and the Retention of Words in Episodic Memory. Journal of Experimental Psychology: General, 104, 268. https://doi.org/10.1037/0096-3445.104.3.268

[37] Baddeley, A. (1992) Working Memory. Science, 255, 556-559. https://doi.org/10.1126/science.1736359 